\title{
Política de Ciência e Tecnologia e Desenvolvimento Nacional: reflexões sobre o plano de ação brasileiro
}

\author{
Marcos Junior Marini ${ }^{1}$ \\ Christian Luiz da Silva²
}

\section{Resumo}

Nas últimas décadas, a agenda das políticas públicas de ciência e tecnologia apresenta a inovação como tese central para a promoção do desenvolvimento nacional. No Brasil, observa-se um grande crescimento nos recursos públicos para esta área. Neste cenário, 0 artigo busca promover uma análise reflexiva sobre o plano de ação brasileiro (Pacti 2007-2010), com uma visão de um prisma integrativo para a ciência, tecnologia e sociedade no contexto do desenvolvimento nacional. A pesquisa está classificada como bibliográfica e documental, com uma abordagem qualitativa a partir da análise de conteúdo dos documentos do MCT do Brasil. 0 estudo revelou que este plano de ação brasileiro continua apresentando a inovação como tese central, com a sua ideologia inserida no contexto da lógica do capital. Como recomendação é indicada a necessidade de incluir aspectos endógenos neste processo, considerando as contribuições da área de CTS para a promoção de um desenvolvimento humano como parte integrante do desenvolvimento nacional.

Palavras-chave: Desenvolvimento nacional. Ciência, tecnologia e sociedade. Políticas de Ciência e Tecnologia. Pacti brasileiro.

\footnotetext{
${ }^{1}$ Aluno do doutorado em Tecnologia da UTFPR - Campus Curitiba -, membro do grupo de pesquisa em Gestão Pública e Desenvolvimento, professor da UTFPR - Campus Pato Branco (PR). marini@utfpr. edu.br

2 Economista, pós-doutor em Administração pela USP, professor do programa de Pós-Graduação em Tecnologia e do departamento de Gestão e Economia da UTFPR, líder do grupo de pesquisa em Gestão Pública e Desenvolvimento da UTFPR. christiansilva@uol.com.br
} 


\begin{abstract}
In recent decades, the public policy agenda for science and technology presents innovation as a central thesis to promote national development. In Brazil, there is a large increase in public resources to this area. In this scenario, this paper to promote a reflective analysis about the Brazilian plan of action (Pacti 2007-2010), with a vision of an integrative perspective for science, technology and society in the context of national development. Research is classified as literature and documents, with a qualitative approach from the content analysis of documents from the MCT of Brazil. The study revealed that the Brazilian plan of action continues to show innovation as a central thesis, with its ideology into the context of capital logic. As recommendations is indicated as the need to include endogenous aspects in this process, considering the contributions of the CTS area to promote human development as an integral part of national development.
\end{abstract}

Keywords: National development. Science, technology and society. Politics of Science and Technology. Brazilian Pacti. 
Analisando as políticas de ciência e tecnologia do Brasil e as condições de desenvolvimento, Viotti (2008) apresenta três fases distintas para o país. A primeira, entre o período após a $2^{a}$ Guerra Mundial e o início dos anos 80, caracterizou-se pela busca do crescimento e do processo de industrialização. A segunda fase correspondeu às últimas duas décadas do século 20, e foi marcada pela busca da eficiência e pela liberalização das forças do mercado (neoliberalismo), com forte influência do Consenso de Washington. Com relação à fase atual, iniciada na virada do século 21, o autor afirma que se busca um novo tipo de desenvolvimento, ainda em construção e indefinido. Nesta fase percebe-se a revalorização das políticas públicas para o desenvolvimento nacional, porém não está ocorrendo uma ruptura com os mecanismos centrados na valorização do mercado (Viotti, 2008).

Ainda com relação à segunda fase, influenciada pelo Consenso de Washington, na qual organismos internacionais como o Fundo Monetário Internacional, o Banco Mundial e o Banco Interamericano de Desenvolvimento influenciaram fortemente as formulações das políticas públicas para países periféricos, é importante ressaltar que não tornou possível um avanço no nível de desenvolvimento destas nações; ao contrário, intensificou os níveis de desigualdades e atendimento às condições sociais.

Nesta direção, Souza (2006, p. 21) destaca que a principal questão para países em desenvolvimento é "como desenhar políticas públicas capazes de impulsionar o desenvolvimento econômico e de promover a inclusão social de grande parte de sua população". Corroborando com esta discussão, Finquelievich (2010), em sua análise sobre as políticas públicas para a sociedade da informação na América Latina, afirma que as políticas nacionais devem ser dirigidas ao aspecto central do desenvolvimento: o desenvolvimento humano.

No Brasil, e na maioria dos países latino-americanos, as políticas públicas desenvolvidas nas últimas décadas do século 20 seguiram os apontamentos dos mecanismos internacionais, conforme já mencionado. $\mathrm{Na}$ área 
de ciência e tecnologia, várias iniciativas e regulamentações foram criadas para, principalmente, incentivar as práticas de inovação e interação entre universidade e empresa.

Durante esta primeira década do século 21, observa-se um grande crescimento nos recursos públicos despendido para a área de ciência e tecnologia e, segundo dados do Ministério da Ciência e Tecnologia, "o dispêndio em C\&T acumulou aumento de mais de R $\$ 8$ bilhões em 2007 e 2008, significando incremento de $138 \%$ em relação ao aumento acumulado no dispêndio do biênio anterior" (Brasil, 2010b, p. 87).

Nestas discussões, situa-se o Plano de Ação em Ciência, Tecnologia e Inovação (Pacti 2007-2010), o qual está sob a responsabilidade do Ministério da Ciência e Tecnologia, e foi denominado: "Ciência, Tecnologia e Inovação para o Desenvolvimento Nacional”. Pelo exposto, observa-se a intenção explícita de ligação entre ciência, tecnologia e inovação como motor para o desenvolvimento nacional.

Assim, surge como problemática principal para este estudo: Quais são as premissas e pressupostos ideológicos que estão presentes neste plano de ação do Ministério da Ciência e Tecnologia (Pacti 2007-2010), e como estão contribuindo para o desenvolvimento nacional? Como principais questões norteadoras para este debate: Como está estruturado o plano? Quais são os principais atores e setores que estão sendo privilegiados? Que influências e priorizações estão presentes no plano? Está priorizando a ciência e tecnologia nacional, possibilitando um desenvolvimento autônomo e independente? Como são articuladas as ações para o desenvolvimento nacional?

Diante desta realidade, como objetivo geral pretende-se analisar a política brasileira de ciência e tecnologia a partir do plano de ação 20072010, com uma visão de um prisma integrativo para a ciência, tecnologia e sociedade no contexto do desenvolvimento nacional. 
Com relação à metodologia quanto aos procedimentos técnicos adotados e o método de investigação, o trabalho está classificado como pesquisa explicativa, utilizando-se dos métodos de pesquisa bibliográfica e documental. O recorte metodológico adotado para objeto de investigação é o plano de ação desenvolvido para o período entre 2007 e 2010. Quanto à abordagem do problema investigado e a interpretação dos dados, pretende-se realizar uma análise qualitativa, de forma crítica e reflexiva, utilizando-se da técnica de análise de conteúdo para este documento editado pelo Ministério da Ciência e Tecnologia do Brasil.

Este artigo está organizado em seis seções, com esta primeira destinada a sua introdução. Em seguida, é apresentada uma seção para a fundamentação teórica das discussões, envolvendo desenvolvimento nacional, ciência e tecnologia.

A terceira seção contempla um breve histórico sobre as políticas de ciência e tecnologia no Brasil. A próxima seção apresenta o Plano de Ação em Ciência, Tecnologia e Inovação (Pacti 2007-2010). A quinta seção destina-se às discussões sobre o objeto de investigação, com uma análise reflexiva das condições do plano com base no tecido conceitual elaborado na fundamentação teórica. A última seção apresenta as considerações finais do presente artigo.

\section{Desenvolvimento Nacional, Ciência e Tecnologia}

As discussões sobre desenvolvimento nacional, ciência e tecnologia são abrangentes, optando-se por um recorte metodológico que contemple algumas discussões e pressupostos para os chamados países periféricos, com o objetivo de subsidiar as reflexões propostas para este artigo. 
Com a revolução industrial ocorreu uma nova formação sociocultural, surgindo os primeiros países capitalistas industriais. Ademais, cria-se uma configuração internacional polarizada, separando os núcleos industriais como economias de alto padrão, e a periferia colonial formada por países que fornecem matéria-prima para a elaboração industrial (Ribeiro, 2000).

Durante meados do século 20 esta divisão é intensificada. "Os países foram classificados, por indicadores de desenvolvimento, em países desenvolvidos, subdesenvolvidos e países em desenvolvimento. O grau de industrialização era quase sinônimo de desenvolvimento" (Heidemann, 2009, p. 26). Assim, o desenvolvimento tornou-se um estado positivo e desejável.

Bielschowsky (1995), analisando a caracterização do subdesenvolvimento como uma condição da periferia, afirma que o conceito centro-periferia fundamenta a teoria da Comissão Econômica para a América Latina e o Caribe (Cepal) em sua tese de que o progresso técnico desenvolveu-se de forma desigual nos dois polos.

Estas condições foram distanciando os países ao longo do tempo e aumentando os problemas sociais nos países chamados periféricos. Analisando o contexto da América Latina, Thomas e Fressoli (2009) destacam os alarmantes índices econômicos e sociais, com $20 \%$ a $50 \%$ da população vivendo em condições de exclusão. A superação destes problemas sociais é o maior desafio para o desenvolvimento nacional nestes países.

Em consonância com estas questões de desenvolvimento, Vieira Pinto (1956, p. 19) assevera que "o desenvolvimento nacional é um processo". Assim, o autor argumenta que não é possível compreender o desenvolvimento nacional como um movimento histórico casual, imprevisto. É necessário interpretá-lo como uma sucessão de aspectos, como uma unidade dinâmica composta pela concatenação de fatos a partir de uma ideia unificadora (Vieira Pinto, 1956). 
Nestas discussões, evidencia-se a necessidade em considerar os aspectos endógenos na formação deste processo e não a busca pela reprodução de um modelo visto como bem-sucedido em outros contextos. Segundo Ramos (2009, p. 67), "nenhuma sociedade em particular, em sua forma episódica contemporânea, pode se caracterizar como paradigmática, como uma sociedade modelar de modernização." Assim, o autor critica a análise baseada em uma sociedade de referência.

Contribuindo com esta questão, Vieira Pinto (1956) em suas discussões sobre o desenvolvimento nacional em meados do século 20, afirma que o Brasil sempre pensou com uma consciência alienada, ou seja, um pensamento colonialista; seu objeto de pensamento é inspirado em outrem, e assim não possui uma consciência autêntica. $\mathrm{O}$ autor sugere uma transmutação da consciência alienada para a consciência autêntica, tomando como base uma ideologia para a nação. Sua tese é que sem ideologia do desenvolvimento não há desenvolvimento nacional, e esta deve ser fenômeno de massa (Vieira Pinto, 1956).

Similarmente, mas analisando a ciência e a tecnologia nos países periféricos, Kreimer (2009) sugere a necessidade de romper com o universalismo, pois em cada contexto o papel social do conhecimento funciona de modo particular. O autor diz que "durante muito tempo as visões convencionais das políticas científicas consideraram que era suficiente formar uma massa crítica de cientistas [...] Assim, a ciência nos países em desenvolvimento funcionaria do mesmo modo que no resto do mundo" (Kreimer, 2009, p. 120).

Dussel (1984) sustenta que nos países capitalistas centrais empregase a ciência cada vez mais para uma condição privilegiada, para a produtividade e o controle e, assim, a ciência está acoplada instrumentalmente à tecnologia. Nesta direção, Santos (2008) argumenta que a técnica e a ciência reforçam a relação entre ciência e produção e, atualmente, a tecnociência situa a base material e ideológica para o discurso e a prática da globalização e do capitalismo. 
É impreterível destacar, contudo, a importância da ciência e da tecnologia para o desenvolvimento das nações. Vieira Pinto ratifica esta condição, argumentando que "em todos os tempos o homem foi um pesquisador [...] O homem tem de pesquisar o mundo onde está para nele produzir condições que lhe permitam sobreviver" (Vieira Pinto, 2005, p. 315). Assim, evidenciase novamente a necessidade de um processo que considere o contexto, analisando as variáveis e condições nas quais estão inseridas.

Kreimer (2009) garante, porém, que muito do conhecimento produzido pela comunidade de pesquisa em países periféricos é "Conhecimento Aplicável e Não Aplicado" (Cana), pois gera estudos que não possuem uma aplicação prática, não sendo revertidos para atender às necessidades da comunidade em que está inserida.

Esta problemática está inserida num cenário mais amplo. Kreimer (2009) critica a subordinação de pesquisadores periféricos aos centros de pesquisa de países centrais, chamando de integração subordinada. O autor assevera que esta subordinação ocorre muitas vezes mediante os programas de doutoramento realizados em países centrais por pesquisadores de países periféricos. Além disto, ele chama a atenção para a "fuga de cérebros", com muitos pesquisadores não retornando para seus países de origem (periféricos). Vieira Pinto (2005) também apresenta esta preocupação, afirmando que o centro metropolitano (países centrais) controla os periféricos, rapta os cientistas promissores e promove na periferia o crescimento da pesquisa por transplantação, num processo de submissão.

Corroborando com as discussões sobre o tecnocentrismo, Dussel declara que muitos pesquisadores atuam como cientificistas, pois exercem ciência "para encobrir e justificar a dominação que o centro e as classes opressoras exercem sobre as nações periféricas e os povos oprimidos" (1996, p. 196). 
Continuando a análise sobre ciência e tecnologia em países periféricos, outra reflexão importante é apresentada por Vieira Pinto (2005), quando sustenta que técnicas aparentemente idênticas apresentam diferenças quando considerados os contextos a serviço de indivíduos ou grupos sociais com finalidades diferentes. Isto é, a mesma mediação material (técnica) muda de significado e valor quando aplicada com finalidades distintas.

Nestas discussões sobre a importância de considerar a história e o contexto, Queluz e Merkle (2010, p. 10) asseveram que "se a sociedade é fruto de um processo histórico e cultural, decorrente do mundo do trabalho, o mundo que se revela através da amanualidade em um país subdesenvolvido, reveste-se de um caráter distinto da dos países desenvolvidos”.

É necessário também adicionar a contribuição de Feenberg (2002) a este debate, quando acrescenta que as sociedades modernas podem tanto seguir um caminho que reforça o poder da elite ou um caminho alternativo que possibilite a sua transformação interna. Assim, o autor faz uma crítica à teoria instrumental da tecnologia, apresentada como uma visão dominante dos governos modernos e da política científica em que eles confiam.

Nesta visão, as tecnologias são ferramentas prontas para servir aos propósitos de seus usuários e, assim, a tecnologia é considerada neutra. Corroborando nesta direção, ressalta-se que os estudos de Ciência, Tecnologia e Sociedade (CTS) também criticam esta visão instrumental da tecnologia, considerando como premissas a não neutralidade da tecnologia, o não determinismo tecnológico e a construção social da tecnologia (Pinch; Bijker, 1997).

Ainda em relação à subordinação de países periféricos aos centrais, Vieira Pinto (2005) argumenta sobre a falta de pensamento crítico dos líderes dos países subdesenvolvidos, aceitando sob qualquer condição a tecnologia exportada pelos dominantes. Mais grave, ainda, é que esta alienação é vista em prol do desenvolvimento nacional. O autor destaca que "nunca o explorador estrangeiro terá interesse em fabricar na região anexa o que 
corresponde ao produto mais elevado de sua invenção. Se há privilégio que jamais abrirá mão é o de inventar, de gerar a técnica" (Vieira Pinto, 2005, p. 273). Assim, o dominador controla a exportação, liberando tecnologia de segunda e terceira linhas, e ainda impelindo a formação da consciência de progresso econômico autônomo.

Com base nas discussões apresentadas nesta seção, e encaminhando para a questão das políticas de ciência e tecnologia, soma-se o papel da comunidade de pesquisa neste processo. Dagnino sinaliza para o papel dominante que a comunidade de pesquisa desempenha na América Latina na elaboração da PCT, afirmando que "na avaliação (por pares) ex-ante, durante, e ex-post, ela alimenta o ciclo de elaboração de políticas com decisões sobre o que deve ser priorizado" (2007, p. 192).

\section{Políticas de Ciência e Tecnologia no Brasil}

Esta seção tem como objetivo apresentar uma breve revisão histórica das principais iniciativas e Políticas de Ciência e Tecnologia (PCT) no Brasil. Para o recorte temporal, apontou-se como marco inicial a criação do Ministério da Ciência e Tecnologia (MCT) em 1985, delimitando, assim, um espaço de 25 anos. Neste mesmo ano foi realizada a $1^{\text {a }}$ Conferência Nacional, visando a discutir estratégias para o setor e discutir os caminhos da pesquisa científica no país, subsidiando definições de políticas públicas para o MCT.

A partir de meados de 1990, as iniciativas e políticas públicas brasileiras para a área de ciência e tecnologia são fortemente influenciadas pelos modelos internacionais, especialmente pelas experiências de países centrais ou desenvolvidos, enfatizando com isso a importância em aspectos econômicos e competitividade, relações universidade-empresa e práticas de 
inovação. Isto fica evidenciado em Viotti (2008), quando o autor afirma que desde o final dos anos 90 a promoção da inovação tecnológica passa a estar explicitamente entre os principais objetivos da política brasileira.

Neste cenário, em 1996 foi criada a Lei de Patentes (lei nº 9.279/96). Esta regulamentação estabelece direitos e obrigações quanto à propriedade industrial, garantindo ao inventor de novo produto, processo ou modelo, a propriedade de sua invenção por um determinado período (Brasil, 2010a).

Outra iniciativa foi a criação em 1999 dos Fundos Setoriais, que são instrumentos de financiamento de projetos de pesquisa, desenvolvimento e inovação no país, centrados na pesquisa científica e tecnológica. Desde a sua instituição, os Fundos Setoriais têm se constituído no principal instrumento do governo federal para alavancar o sistema de CT\&I (Finep, 2010).

Em 2001 foi elaborado o Livro Verde pelo MCT, apresentando a importância da inovação em seu título: "Ciência, tecnologia e inovação: desafio para a sociedade brasileira" (Brasil, 2001). Este livro foi utilizado como referência para as discussões da Conferência Nacional de Ciência, Tecnologia e Inovação (CNCTI), realizadas neste mesmo ano. Com esta premissa, a segunda conferência nacional apresentou a necessidade de incorporar a inovação nas políticas de C\&T e incentivar a inovação nas empresas brasileiras. Evidencia-se, assim, a transformação explícita da PCT em PCT\&I. Como resultado da $2^{\text {a }}$ CNCTI foi lançado, em 2002, o Livro Branco.

De modo geral, o Livro Branco discute questões para a formação de um Sistema Nacional de Ciência, Tecnologia e Inovação, destacando a sua importância percebida no cenário internacional. "A experiência internacional demonstra que Ciência, Tecnologia e Inovação desempenham papel fundamental na criação de um círculo virtuoso de crescimento" (Brasil, 2002, p. 24).

Como consequência destas discussões, o Livro Branco apresenta seis objetivos para uma política nacional de CT\&I: criar um ambiente favorável à inovação; ampliar a capacidade de inovação e expansão da base científica e 
tecnológica; aperfeiçoar, consolidar e modernizar o aparato institucional de CT\&I; promover a integração de todas as regiões brasileiras, minimizando as diferenças regionais; conquistar amplo apoio para as políticas de CT\&I; incorporar CT\&I como elemento estratégico da política nacional de desenvolvimento (Brasil, 2002).

Em continuidade, visando a atender uma das diretrizes estratégicas definidas no Livro Branco, em 2002 foi elaborada a Política Nacional de CT\&I, estabelecendo objetivos a serem alcançados num espaço de 10 anos. Assim, reforça-se novamente a importância da inovação como elemento de base para a agenda da política científica e tecnológica do país.

No âmbito destas discussões, ressalta-se ainda a Lei de Inovação, a qual surgiu como uma das propostas discutidas na $2^{\text {a }}$ CNCTI, e introduzida por meio da Lei ${ }^{\circ} 10.973 / 04$. Esta lei define mecanismos de incentivo a CT \&I, com subvenção a empresas inovadoras, incentivos à incubação de empresas no espaço público e à participação do pesquisador público nos processos de inovação tecnológica desenvolvidos em parcerias com empresas privadas (Brasil, 2010a). Pelo exposto, observa-se que a Lei de Inovação é um instrumento legal para propiciar uma maior interação entre as esferas do governo, comunidade científica e as empresas privadas, realçando o modelo universidade-empresa.

O plano de gestão do Ministério da Educação para o período entre 2003 e 2006 também orientou-se pela centralidade da ciência, tecnologia e inovação (CT\&I), com o desenvolvimento e a efetivação de uma Política Nacional de Ciência, Tecnologia e Inovação (PNCTI). Conforme o Relatório de Gestão do Ministério da Ciência e Tecnologia para este período, esta política baseou-se em quatro eixos estratégicos: expansão, consolidação e integração do Sistema Nacional de CT\&I; promoção da Política Industrial, Tecnológica e de Comércio Exterior (PITCE); investimentos em programas estratégicos para a soberania nacional; C\&T para a inclusão e o desenvolvimento social (Brasil, 2006). 
Em 2005 foi realizada a $3^{\text {a }}$ Conferência Nacional de Ciência, Tecnologia e Inovação, objetivando analisar a PCT\&I e discutir estratégias e ações para promover o desenvolvimento do país. A sua ênfase principal focaliza as atividades de CT\&I como essenciais para o desenvolvimento do Brasil. Como resultado desta conferência, foi lançado o Livro Amarelo.

Nesta direção, outra legislação criada foi a Lei do Bem (Lei ${ }^{\circ}$ 11.196/05), com incentivos para o abatimento de gastos com inovação pelas empresas, redução de alíquota do IPI incidente sobre aquisição de recursos físicos para pesquisa e desenvolvimento tecnológico, e subvenção de $60 \%$ na remuneração de mestres e doutores envolvidos com atividades de inovação em empresas (Brasil, 2010a). Complementarmente, em 2007 foi regulamentada a Lei Rouanet da Pesquisa (Lei n ${ }^{\circ}$ 11.487/07), modificando a Lei do Bem e incluindo a isenção fiscal para empresas que atuarem em parceria com instituições científicas e tecnológicas (ICTs).

Seguindo a apresentação das principais iniciativas e Políticas de Ciência e Tecnologia (PCT) no Brasil, situa-se o Plano de Ação em Ciência, Tecnologia e Inovação (Pacti 2007-2010), vinculado ao Ministério da Ciência e Tecnologia. Este plano de ação é o principal objeto de pesquisa deste artigo, optando-se pelo seu detalhamento na próxima seção.

Como última iniciativa para o espaço temporal definido para esta breve revisão histórica, destaca-se a realização em 2010 da 4 a Conferência Nacional de Ciência, Tecnologia e Inovação, com o tema: "Política de Estado para Ciência, Tecnologia e Inovação com vistas ao Desenvolvimento Sustentável". As discussões objetivaram elaborar diretrizes para a consolidação de um Sistema Nacional articulado que promova a efetiva cooperação entre os âmbitos federal, estadual e municipal, consolidando a Política Nacional de Ciência, Tecnologia e Inovação (CGEE, 2010).

No âmbito desta $4^{\text {a }}$ CNCTI, merece destaque a inclusão da representação dos movimentos sociais por meio da participação da Rede de Tecnologia Social (RTS) na comissão organizadora do evento (RTS, 2010). 
Como resultado das discussões desta $4^{a}$ CNCTI realizada em 2010, está em construção o Livro Azul, contendo uma síntese dos grandes temas abordados nesta conferência.

\section{Plano de Ação em Ciência, Tecnologia e Inovação (Pacti 2007-2010)}

Esta seção buscará a caracterização deste plano de ação, identificando sua abrangência, suas metas e principais objetivos, prioridades estratégicas e linhas de ação previstas. O principal objetivo é a formação de uma base teórica com elementos que possam subsidiar as discussões da seção seguinte. Salienta-se, portanto, que a seção não pretende discutir e analisar o plano, apenas apresentar seus referenciais.

O Plano de Ação em Ciência, Tecnologia e Inovação (Pacti 20072010) está sob a responsabilidade do Ministério da Ciência e Tecnologia, denominado: "Ciência, Tecnologia e Inovação para o Desenvolvimento Nacional". Neste sentido, cabe destacar a sua importância e abrangência para o governo deste período, constituindo-se num mecanismo integrado com as demais políticas governamentais. Isto é observado na configuração política apresentada no plano:

O Ministério da Ciência e Tecnologia (MCT) vem se orientando para o desenvolvimento e a implementação de uma Política Nacional de Ciência, Tecnologia e Inovação de forma integrada às demais políticas de governo, articulando-se numa visão sistêmica e harmônica, de maneira a constituir um planejamento integrado, o que necessariamente envolve diversos atores institucionais (Brasil, 2007a, p. 30).

Este planejamento integrado das políticas públicas do governo federal inclui também a sua integração com o Programa de Aceleração do Crescimento e Infraestrutura (PAC). Assim, o Pacti está organizado numa matriz sistêmica que promove a interação dos seguintes representantes: Ministério da Ciência e Tecnologia (MCT), Ministério da Educação (MEC), 
Ministério de Minas e Energia (MME), Ministério da Agricultura, Pecuária e Abastecimento (MAPA), Ministério da Defesa (MD), Ministério do Desenvolvimento, Indústria e Comércio Exterior (MDIC), Ministério das Comunicações (MC), Ministério da Saúde (MS) (Brasil, 2007a).

A formulação deste plano para o período entre 2007-2010 apresenta as seguintes metas: aumentar os percentuais de investimentos em P\&D, promover a inovação nas empresas, aumentar o número de bolsas para formação de recursos humanos, criar centros vocacionais tecnológicos e telecentros, ampliar a Olimpíada de Matemática e incentivar com a concessão de bolsas para alunos do Ensino Médio (Brasil, 2007a).

Para o cumprimento destas metas, o plano contempla seis principais objetivos, assim propostos pelo MCT (Brasil, 2007a, p. 41):

- Aperfeiçoar as instituições, a gestão e a governança da política de CT\&I;

- Expandir e consolidar a capacidade de pesquisa científica e tecnológica do País, ampliando de forma substancial o apoio financeiro à ciência e tecnologia em geral e à formação e à fixação de recursos humanos, priorizando as engenharias e as áreas relacionadas com a Política Industrial, Tecnológica e de Comércio Exterior (PITCE);

- Ampliar o apoio à inovação e ao desenvolvimento tecnológico das empresas, acelerando o desenvolvimento de tecnologias avançadas e de setores portadores de futuro e massificando programas de extensão e capacitação tecnológica, com ênfase nas empresas de micro, pequeno e médio porte;

- Fortalecer as atividades de P\&D e de inovação em áreas estratégicas para o crescimento e o desenvolvimento do País, com ênfase em Tecnologias da Informação e Comunicação, Insumos para a Saúde, Biocombustíveis, Agronegócios e o Programa Nuclear;

- Contribuir para o desenvolvimento e a eqüidade regional e social, em especial das regiões Centro-Oeste, Nordeste e Norte; e,

- Popularizar a ciência e promover a geração, a difusão e o uso de conhecimentos para a melhoria das condições de vida da população. 
Considerando as metas e objetivos estabelecidos, o plano está composto por uma estrutura assentada em 4 prioridades estratégicas e 21 linhas de ação, formando um conjunto de 87 programas. Com o propósito de criar um arcabouço teórico para as discussões que serão apresentadas na próxima seção deste artigo, a seguir será resumida a composição deste planejamento.

A primeira prioridade estratégica é a "Expansão e Consolidação do Sistema Nacional de CT\&I". Para isto, são propostas três linhas de ação: consolidação institucional do Sistema Nacional de CT\&I; formação de recursos humanos para CT\&I; infraestrutura e fomento da pesquisa científica e tecnológica (Brasil, 2007a).

Outra prioridade estratégica é a "Promoção da Inovação Tecnológica nas Empresas". Suas linhas de ação previstas: apoio à inovação tecnológica nas empresas; tecnologia para a inovação nas empresas; incentivo à criação e à consolidação de empresas intensivas em tecnologia (Brasil, 2007a).

Como terceira prioridade estratégica do plano, apresenta-se a "Pesquisa, Desenvolvimento e Inovação em Áreas Estratégicas”. São definidas 13 linhas de ação: áreas portadoras de futuro como biotecnologia e nanotecnologia; tecnologias da informação e comunicação; insumos para a saúde; biocombustíveis; energia elétrica, hidrogênio e energias renováveis; petróleo, gás e carvão mineral; agronegócio; biodiversidade e recursos naturais; Amazônia e semiárido; meteorologia e mudanças climáticas; programa espacial; programa nuclear; defesa nacional e segurança pública (Brasil, 2007a).

A quarta prioridade estratégica está definida como "CT\&I para o Desenvolvimento Social”. São previstas duas linhas de ação: popularização da CT \&I e melhoria do ensino de ciências; e tecnologias para o desenvolvimento social (Brasil, 2007a).

Nestas quatro prioridades estratégicas estão representados, respectivamente, os principais atores que participam deste fórum, assim constituído: comunidade de pesquisa, empresa, governo e os movimentos sociais. 
Segundo Dagnino e Bagattolli (2009, p. 156), “o peso relativo dos mesmos corresponde ao poder político referente à participação de cada ator no processo decisório da PCT".

\section{Análises e discussões}

Nesta seção será apresentada uma análise reflexiva do plano que está definido como objeto de estudo para este artigo, com base no tecido conceitual que foi elaborado na sua fundamentação teórica. A abordagem será construída a partir das discussões de suas premissas, do principal objetivo, permitindo a identificação da ideologia presente neste plano de ação. $\mathrm{Na}$ sequência serão discutidos aspectos do orçamento previsto em sua elaboração, possibilitando identificar as áreas e setores privilegiados, os principais eixos e interesses representados. Como reflexão final da seção discute-se aspectos sobre a articulação da ciência e tecnologia ao desenvolvimento nacional, numa visualização do plano de ação e seu contexto para o desenvolvimento nacional.

O Plano de Ação em Ciência, Tecnologia e Inovação (Pacti 2007-2010) apresenta em sua fundamentação quatro premissas, as quais orientaram a sua formulação. Segundo o MCT (Brasil, 2007b, p. 21), "estas premissas, ao ressaltarem a situação desfavorável do Brasil, ao ser comparado com países mais avançados, [...] embasaram e justificaram os componentes do plano". Observa-se, assim, que a sua justificativa busca o alinhamento comparativo com o contexto dos países centrais.

Como primeira premissa, o plano destaca uma forte correlação entre o grau de desenvolvimento de um país alinhado aos seus esforços a partir dos investimentos em pesquisa e desenvolvimento (P\&D) e pela capacidade de sua comunidade de pesquisa (Brasil, 2007b). Esta premissa sustenta, portanto, a necessidade de ampliar os investimentos em pesquisa e desen- 
volvimento e fortalecer a comunidade de pesquisadores, evidenciando uma forte necessidade de aplicação de recursos nesta área bem como a relação entre pesquisadores e desenvolvimento.

Neste aspecto, é importante observar Dagnino (2006) quando argumenta que se por um lado a comunidade de pesquisa estaria aceitando delegar parte de sua agenda de pesquisa a outros atores, como no maior atendimento às demandas e interações com as empresas, por outro estaria pleiteando um lugar ainda mais privilegiado que não contrarie seus interesses. Assim, observa-se uma predominância da comunidade de pesquisa nestas discussões de políticas públicas para ciência e tecnologia.

A segunda premissa reforça ainda mais estes apontamentos, ao afirmar que "os países com economias desenvolvidas têm forte atividade de pesquisa, desenvolvimento e inovação nas empresas, financiadas por elas próprias e pelo governo" (Brasil, 2007b, p. 13). Ademais, esta premissa ratifica a comparação com países centrais, apontando ainda para a necessidade de aproximação entre centros de pesquisa e empresas, com uma indicação de financiamento público para atender a estas atividades.

Nesta direção, o plano previa uma taxa de 1,5\% do Produto Interno Bruto (PIB) para investimentos em P\&D, porém, apesar dos esforços públicos, este índice não foi alcançado. Segundo dados do relatório MCT (Brasil, 2010b, p. 88), “após análise dos dados de 2007 e 2008, estima-se que a proporção do dispêndio em P\&D em relação ao PIB será de 1,22\% em 2010. Esta taxa corresponde a um alcance de $81 \%$ da originalmente fixada como meta no plano de ação". Ressalta-se ainda que este relatório aponta para a necessidade de aumentar o investimento privado no financiamento das atividades da área, o qual ficou abaixo das expectativas. 
A terceira premissa faz novamente referência aos países centrais, afirmando que o desenvolvimento econômico destes países foi possível pela articulação entre políticas industriais e políticas de CT\&I (Brasil, 2007b). Como resultado desta articulação, percebe-se uma tentativa de maior aproximação entre os meios acadêmico e empresarial.

Dagnino (2006, p. 196), discutindo sobre as universidades, assevera que "elas são sistemas fechados, pouco interessados na cooperação com empresas, nem na comercialização de resultados de pesquisa”. O autor ainda argumenta que a pesquisa pública é lenta e muito intensiva em tempo, sem mecanismos que estimulem esta interação. Logo, observa-se uma incoerência entre a estrutura acadêmica existente no país e os encaminhamentos práticos que estão previstos neste plano.

Como última premissa para este plano, evidencia-se a capacidade brasileira, indicando novamente a comparação com os países centrais. "O Brasil encontra-se em situação intermediária, no mundo, em termos de capacidade produtiva e acadêmica, mas dispõe de massa crítica para uma gradual aproximação aos níveis tecnológicos das economias desenvolvidas" (Brasil, 2007b, p. 18).

Em síntese, as quatro premissas apresentam como forte eixo de estruturação os dados comparativos entre a realidade nacional e as práticas desenvolvidas nos países centrais. Em contrapartida, muitas discussões apresentadas na fundamentação teórica indicaram para a necessidade de uma ruptura com estes modelos paradigmáticos, nos quais se adota uma sociedade de referência. Nestas discussões, é impreterível salientar a necessidade em se considerar várias dimensões, observando as condições e os fatores endógenos para o desenvolvimento, evitando-se a armadilha da tecnociência como discurso ideológico do capitalismo. Corroborando nesta direção, Finquelievich (2010, p. 15) afirma que: 
As políticas públicas para a sociedade da informação na América Latina, no campo da ciência, tecnologia e inovação, devem considerar antes de tudo o contexto, as necessidades e as demandas nacionais, considerando além das recomendações e das melhores práticas internacionais.

Seguindo com a análise, encaminha-se para o principal objetivo apresentado neste plano: "criar as condições para que as empresas brasileiras acelerem de maneira significativa a geração e a absorção de inovações tecnológicas, capacitando-as a agregar valor à sua produção e a aumentar sua competitividade" (Brasil, 2007a, p. 33). Esta informação do Ministério da Ciência e Tecnologia confirma o que já foi mencionado anteriormente, ou seja, a fase atual, apesar de ainda estar em construção e indefinida, privilegia mecanismos de valorização do mercado, apresentando fortes ligações com as visões de desenvolvimento que balizaram a fase anterior.

Outra análise importante é possível pelo próprio título e subtítulo apresentado na capa deste documento: "Ciência, Tecnologia e Inovação para o Desenvolvimento Nacional: Investir e inovar para crescer”. Isto destaca a priorização da ciência e da tecnologia para o desenvolvimento nacional, amparados fortemente pela inovação.

Crescimento, todavia, não é sinônimo de desenvolvimento, pois este último é mais amplo e contempla várias dimensões além da visão puramente econômica do crescimento. $\mathrm{O}$ desenvolvimento nacional não pode ser visto e projetado apenas por meio de números como produto interno bruto (PIB) e outras taxas de crescimento. Assim, no mínimo, sugere-se um subtítulo mais condizente com a realidade do desenvolvimento nacional, podendo ser: "Investir para desenvolver nosso País".

É oportuno mencionar também que este plano de ação situa-se num conjunto maior de medidas desenvolvidas neste período pelo governo federal, chamado Programa de Aceleração do Crescimento (PAC). Assim, o plano "foi concebido como outro destacado elemento do conjunto do Plano de Governo e constitui-se em uma base para que se possa construir rapidamente um verdadeiro PAC da Inovação" (Brasil, 2007a, p. 32). 
Novamente está presente como tese central a inovação para o desenvolvimento nacional. Assim, é imprescindível recorrer às bases que sustentam esta teoria. Dagnino (2009, p. 92) afirma que "o conceito de inovação foi cunhado no contexto dos países de capitalismo avançado [...] tem como objetivo melhorar a condição de uma empresa frente à concorrência intercapitalista e não para promover o bem-estar social".

Compilando estas discussões, observa-se que este plano de ação possui mecanismos que buscam uma fina sintonia com o mercado, e, portanto, está inserido no contexto da lógica do capital, o que caracteriza suas premissas e sua ideologia de formulação e instituição.

Neste contexto, é importante considerar o orçamento que foi previsto para a consolidação deste plano de ação. Segundo dados do Ministério da Ciência e Tecnologia, na formulação do Pacti (2007-2010) foram previstos recursos federais para um orçamento em torno de $\mathrm{R} \$ 41$ bilhões (Brasil, 2007a). A Figura a seguir apresenta o percentual de recursos estimados para cada uma das quatro prioridades estratégicas citadas anteriormente, considerando o período entre 2007 e 2010.

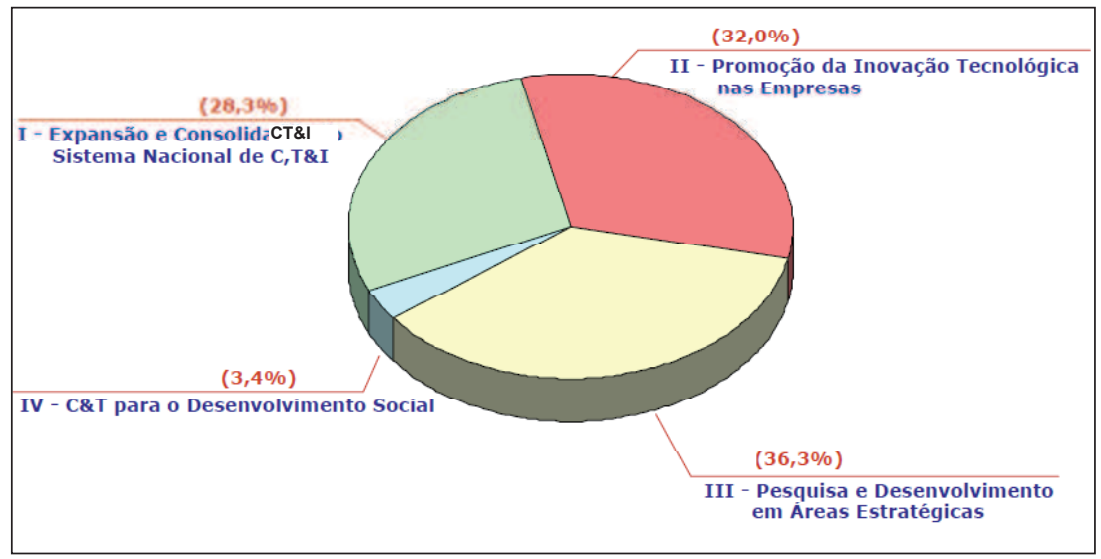

Figura 1 - Total de recursos estimados por prioridade estratégica (2007-2010) Fonte: Adaptado de Pereira (2007). 
Ainda nestas discussões sobre os recursos financeiros para o Pacti (2007-2010), segundo dados do relatório apresentado pelo Ministério da Ciência e Tecnologia em maio de 2010, considerando o total do orçamento executado entre 2007 e 2009 e os valores previstos para 2010, serão gastos $\mathrm{R} \$ 40,3$ bilhões, o que corresponde a 97,9\% da previsão inicial (Brasil, 2010b).

Com base na Figura 1, é possível identificar os setores e as áreas priorizadas no orçamento deste plano de ação. Assim, percebe-se que apenas três das quatro prioridades estratégicas definidas para o plano apresentam uma prioridade no orçamento previsto e efetivado. De forma geral, além da pesquisa e desenvolvimento de áreas estratégicas para o país (biotecnologia, nanotecnologia, biocombustíveis, energias renováveis, programa espacial, programa nuclear, defesa nacional e segurança pública, entre outras), o plano prioriza a ampliação da inovação nas empresas e a consolidação do sistema nacional de CT \&I, com grande influência da comunidade de pesquisa.

Diante desta realidade, apresentam-se como áreas priorizadas o apoio público à pesquisa e desenvolvimento em empresas privadas, bem como os incentivos para a comunidade de pesquisa.

Com relação ao apoio público à área de $\mathrm{P} \& \mathrm{D}$ em empresas privadas, o plano menciona que "é uma prática comum aos países desenvolvidos, admitida pela Organização Mundial do Comércio” (Brasil, 2007a, p. 50). Além disso, este financiamento público é justificado com a afirmação de que, mesmo correspondendo a uma prática comum em países europeus, ainda apresenta-se em grau reduzido no Brasil. Com este propósito, no plano estão previstas ações como: apoio a financiamentos para empresas privadas com juros reais reduzidos, incentivos fiscais e subvenção econômica.

No que se refere à subvenção econômica, foram criados mecanismos na legislação brasileira visando a ampliar o seu alcance, como a Lei do Bem em 2005, prevendo subvenção de até $60 \%$ na remuneração de pesquisadores envolvidos com atividades inovativas nas empresas privadas. Em 2007, a Lei 
Rouanet da Pesquisa amplia esta possibilidade, estimulando, por meio da isenção fiscal, aquelas empresas que atuam em parcerias com instituições científicas e tecnológicas, como universidades e centros de pesquisa.

Nas discussões sobre esta importância atribuída para a relação universidade-empresa, Dagnino e Bagattolli (2009, p. 164) afirmam que "a tentativa de aumentar a interação universidade-empresa (esforço de mais de quarenta anos), não parece estar surtindo efeito". Os autores argumentam que a maior parte das empresas consideram este processo de pouca importância, e ainda revelam outro problema, pois os maiores investimentos empresariais são na aquisição de máquinas e equipamentos enquanto atividade inovativa. $\mathrm{O}$ relatório OECD (Organization for Economic Co-operation and Development) também destaca estas questões, evidenciando que poucas empresas brasileiras cooperam com universidades e preferem inovar por meio de máquinas e equipamentos (Brasil, 2008).

A comunidade de pesquisa é outra área que recebe uma grande atenção neste plano de ação e nas políticas de ciência e tecnologia vigentes, com a ampliação das possibilidades de parcerias e interações com as empresas privadas. O plano ainda prevê incentivos para a produção científica e abertura de novas linhas de pesquisa nos programas de Pós-Graduação. Nos últimos anos foi constatado um aumento expressivo no número das bolsas fornecidas pelo CNPq para todas as modalidades (Brasil, 2007a).

$\mathrm{Na}$ análise da Figura 1 é importante destacar ainda que, apesar de incluir a ciência e a tecnologia para o desenvolvimento social como uma das quatro prioridades estratégicas, observa-se um grande distanciamento com relação às demais áreas. O plano de ação prioriza em demasia a tecnologia convencional, e as verbas destinadas para a agenda dos movimentos sociais somam um pouco mais que $3 \%$ de todo o orçamento previsto para a sua consolidação. 
Diante do exposto, como análise final sobre a articulação da ciência e tecnologia para o desenvolvimento nacional, salienta-se que o plano busca seguir uma estratégia ou modelo praticado pelos países centrais, nos quais a inovação aparece como elemento fundamental, num processo intensivo para ampliar a competitividade empresarial e fortalecer o mercado para a concorrência global.

Segundo Dias e Novaes (2009, p. 58), "a inovação tecnológica seria, portanto, um fenômeno essencialmente capitalista". O modelo baseado na inovação representa o processo capitalista, inspirado pelas práticas deterministas e reflexões dos países centrais. Assim, argumenta-se sobre a necessidade de uma maior reflexão sobre a realidade nacional, permeada por uma consciência crítica ou autêntica, como sugerido por Vieira Pinto (2005), e não apenas por uma reprodução das práticas desenvolvidas nos países centrais.

Ademais, outras contribuições que formaram o tecido conceitual para a fundamentação teórica deste artigo, evidenciam pistas e apontam para uma necessidade de superar a teoria instrumental da tecnologia, romper com o universalismo, o determinismo tecnológico e a visão de neutralidade da ciência e tecnologia, considerando um movimento de formulação de políticas públicas para a área de ciência e tecnologia que possa emergir de ampla discussão com os diversos atores sociais.

Nesta análise, é importante considerar que não está sendo proposto um movimento contrário à ciência e à tecnologia, mas, como afirma Dussel (1996, p. 196), "a ciência e a tecnologia são necessárias para o processo de libertação das nações e das classes periféricas e populares”. Logo, mira-se para um novo horizonte possível, com a ciência e a tecnologia representando os interesses de desenvolvimento nacional de forma integral e autônoma.

Esta argumentação sustenta-se em vários apontamentos observados na literatura, como os de Dussel (1984, p. 236), quando argumenta que é necessário "um programa concreto de prioridades que sirva de fonte de cri- 
térios para definir uma estratégia de desenvolvimento correspondente a um projeto novo de sociedade”. Nesta direção, Dagnino (2009) cita a tecnologia social como possibilidade para a construção de outra sociedade.

Dias e Novaes (2009) destacam que a tecnologia social possui como alicerce a solidariedade e a participação dos produtores e usuários. Assim, são estimulados mecanismos de autogestão e participação democrática, considerando-se o contexto social, espacial, econômico, político e institucional. Ressalta-se, assim, uma aproximação com o conceito que é discutido em Ciência, Tecnologia e Sociedade (Estudos CTS) sobre a construção social da tecnologia.

Não obstante, é oportuno não confundir tecnologia social apenas como sinônimo de inclusão social. Analisando a prioridade estratégica de ciência e tecnologia para o desenvolvimento social do plano de ação, na qual deveriam estar contempladas as discussões da tecnologia social, observa-se que as ações definidas estão mais direcionadas para a inclusão social, com o objetivo de promover a popularização e o ensino de ciências nas escolas, bem como a difusão de tecnologias para a inclusão social. Assim, é possível afirmar também que o plano em análise apresenta poucas interações com a área de tecnologia social como estratégia para o desenvolvimento nacional.

\section{Considerações Finais}

A inovação tecnológica está compondo explicitamente a agenda das políticas públicas de ciência e tecnologia no Brasil desde meados dos anos 90. Neste cenário, podem ser citadas várias iniciativas e instrumentos legais, como a Lei de Patentes em 1996, a criação dos Fundos Setoriais em 1999, o Livro Verde que fundamentou as discussões da $2^{\text {a }}$ CNCTI realizada em 2001, a própria Lei de Inovação de 2004, entre outros. 
Neste cenário, o artigo buscou promover uma análise reflexiva da política brasileira de ciência e tecnologia a partir do plano de ação 20072010, com uma visão de um prisma integrativo para a ciência, tecnologia e sociedade no contexto do desenvolvimento nacional.

Assim, a partir das premissas deste plano de ação, observou-se uma forte articulação entre a formulação deste plano e as práticas desenvolvidas nos países centrais, com a intenção explícita de promover a ciência, tecnologia e inovação como motor para o desenvolvimento nacional.

Em síntese, apesar desta fase atual estar ainda em construção, apresenta fortes ligações com as ações que balizaram a fase anterior, e a inovação continua presente em sua tese central. Ademais, percebe-se a introdução de mecanismos que buscam uma fina sintonia com o mercado e com a sua ideologia permeada pelo contexto da lógica do capital. Neste cenário, foram identificadas como áreas priorizadas o apoio público à pesquisa e desenvolvimento em empresas privadas, bem como os incentivos para a comunidade de pesquisa.

Em contrapartida, as discussões da fundamentação teórica apontam para a necessidade de ruptura com estes modelos paradigmáticos, com a inclusão dos aspectos endógenos na formação deste processo. Nesta direção, é importante considerar as contribuições dos estudos de Ciência, Tecnologia e Sociedade (CTS), os quais criticam esta visão universal e instrumental da tecnologia, e consideram uma análise fundamentada nas premissas da não neutralidade da tecnologia, do não determinismo tecnológico e da necessidade de construção social da tecnologia.

Diante do exposto, como alinhamento das políticas de ciência e tecnologia ao desenvolvimento nacional, numa visão mais ampla do termo, é imprescindível a formulação e instituição de uma Política de Ciência e Tecnologia capaz de promover o desenvolvimento humano como parte integrante do desenvolvimento nacional, com a participação democrática 
e igualitária dos diversos atores sociais, possibilitando que a ciência e a tecnologia atendam ao contexto social, ou seja, promovam uma relação multidirecional entre ciência e tecnologia e sociedade.

Como encaminhamento para trabalhos futuros, sugere-se a investigação sobre as recentes políticas de ciência e tecnologia em outros países latino-americanos, utilizando-se os indicativos dos estudos de ciência, tecnologia e sociedade (CTS) como ferramenta de análise para este cenário. Complementarmente, será possível compor um quadro teórico para análise das ações e estratégias adotadas nos diversos contextos destes países.

\section{Referências}

BIELSCHOWSKY, R. Pensamento econômico brasileiro: o ciclo ideológico do desenvolvimentismo. 2. ed. Rio de Janeiro: Contraponto, 1995.

BRASIL. MCT. Ministério da Ciência e Tecnologia. Brasília, 2010a. Disponível em: $<$ http://www.mct.gov.br>. Acesso em: 20 nov. 2010.

BRASIL. MCT. Livro verde. Ciência, tecnologia e inovação: desafio para a sociedade brasileira. Cylon Gonçalves da Silva e Lúcia Carvalho Pinto de Melo (Coords.). Brasília: Ministério da Ciência e Tecnologia; Academia Brasileira de Ciências, 2001.

BRASIL. MCT. Livro branco: Ciência, tecnologia e inovação. Brasília: MCT, 2002.

BRASIL. MCT. Relatório de Gestão 2003-2006. Brasília: MCT, 2006. Disponível em: <http://www.mct.gov.br/index.php/content/view/50870.html>. Acesso em: 19 nov. 2010.

BRASIL. MCT. Versão completa - Plano de Ação em Ciência, Tecnologia e Inovação (PACTI 2007-2010). Brasília: MCT, 2007a. Disponível em: <http://www.mct.gov.br/ index.php/content/view/66226.html>. Acesso em: 19 nov. 2010.

BRASIL. MCT. Documento Sintese - Plano de Ação em Ciência, Tecnologia e Inovação (PACTI 2007-2010). Brasília: MCT, 2007b. Disponível em: <http://www.mct. gov.br/index.php/content/view/66226.html>. Acesso: 19 nov. 2010. 
BRASIL. MCT. Principais Resultados e Avanços do Plano de Ação em Ciência, Tecnologia e Inovação para o Desenvolvimento Nacional (Período 2007-2009). Brasília: MCT, 2010b. Disponível em: <http://www.mct.gov.br/index.php/content/view/66226. html>. Acesso em: 19 nov. 2010.

CGEE. Centro de Gestão e Estudos Estratégicos. $4^{\mathrm{a}}$ Conferência Nacional de Ciência, Tecnologia e Inovação. Disponível em: <http://cncti4.cgee.org.br>. Acesso em: 20 nov. 2010.

DAGNINO, R. P. A comunidade de pesquisa dos países avançados e a elaboração da política de ciência e tecnologia. Revista Brasileira de Ciências Sociais, v. 21, n. 61, jun. 2006.

DAGNINO, R. P. Ciência e tecnologia no Brasil: o processo decisório e a comunidade de pesquisa. Campinas: Editora da Unicamp, 2007.

DAGNINO, R. P. Em direção a uma teoria crítica da tecnologia. In: DAGNINO, R. P. (Org.). Tecnologia social: ferramenta para construir outra sociedade. Campinas: IG; Unicamp, 2009.

DAGNiNO, R. P.; BAGATTOLLI, C. Como transformar a tecnologia social em política pública? In: DAGNINO, R. P. (Org.). Tecnologia social: ferramenta para construir outra sociedade. Campinas: IG; Unicamp, 2009.

DIAS, R. de B.; NOVAES, H. T. Contribuições da Economia da Inovação para a reflexão acerca da tecnologia social. In: DAGNINO, R. P. (Org.). Tecnologia social: ferramenta para construir outra sociedade. Campinas: IG; Unicamp, 2009.

DUSSEL, E. Filosofía de la Producción. Bogotá: Nueva America, 1984. Disponível em: <http://www.ifil.org/dussel>. Acesso em: 26 nov. 2010.

DUSSEL, E. Filosofía de la Liberación. Bogotá: Nueva America, 1996. Disponível em: <http://www.ifil.org/dussel>. Acesso em: 26 nov. 2010.

FEENBERG, A. A teoria crítica da tecnologia: a crítica da racionalidade técnicocientífica. In: Racionalização subversiva: tecnologia, poder e democracia. Tradução de Carlos Alberto Jahn, 2002.

FINEP. Financiadora de Pesquisas e Projetos. Fundos Setoriais. Disponível em: $<$ htttp://www.finep.gov.br/fundos_setoriais/fundos_setoriais_ini.asp>. Acesso em: 21 nov. 2010. 
FINQUELIEVICH, S. Sistemas regionales de innovación: las políticas públicas para la sociedad de la información en América Latina. Revista Iberoamericana de Ciencia, Tecnología y Sociedad, Buenos Aires, v. 5, n. 15, set./2010.

HEIDEMANN, F. G. Do sonho do progresso às políticas de desenvolvimento. In: HEIDEMANN, F. G.; SALM, J. F. (Orgs.). Políticas públicas e desenvolvimento: bases epistemológicas e modelos de análise. Brasília: Editora UNB, 2009.

KREIMER, P. Ciencia y Periferia. In: KREIMER, P. El Cientifico también es un Ser Humano. Buenos Aires: Siglo Veinteuno Editores, 2009.

OECD. Organization for Economic Co-operation and Development. In: OECD Science, Technology and Industry. Outlook 2008. Science and Innovation: Country Notes, 2008.

PEREIRA, G. H. Apresentação Plano de Ação 2007-2010. Secretário de Desenvolvimento Tecnológico e Inovação. Brasília: Ministério da Ciência e Tecnologia, 2007. Disponível em: <http://www.mudancasclimaticas.andi.org.br>. Acesso em 22 nov. 2010.

PINCH, T.; BIJKER, W. The social construction of facts and artifacts: or how the Sociology of Science and the Sociology of Technology might benefit each other. In: The Social Construction of Technological Systems. Cambridge, Mass: MIT Press, 1997.

QUELUZ, G. L.; MERKLE, L. E. Ciência, Tecnologia, Sociedade e Cultura: as contribuições de Álvaro Vieira Pinto e Darcy Ribeiro ao Placts nas décadas de 195060. In: VIII Jornadas latinoamericanas de estudios sociales en la ciencia y tecnología. Buenos Aires: Sociedad Latinoamericana de Estudios Sociales de la Ciencia y la Tecnología (Sociedad Esocite), 2010.

RAMOS, A. G. A modernização em nova perspectiva: em busca do modelo da possibilidade. In: HEIDEMANN, F. G.; SALM, J. F. (Orgs.). Políticas públicas e desenvolvimento: bases epistemológicas e modelos de análise. Brasília: Editora UNB, 2009.

RIBEIRO, D. O processo civilizatório. São Paulo: Cia das Letras, 2000.

RTS. Rede de Tecnologia Social. Disponível em: <http://www.rts.org.br>. Acesso em: 23 nov. 2010.

SANTOS, M. A natureza do espaço: técnica e tempo. Razão e emoção. São Paulo: Edusp, 2008. 
SOUZA, C. Políticas públicas: uma revisão da literatura. Sociologias, Porto Alegre, ano 8, n. 16, p. 20-45, jul./dez. 2006.

THOMAS, H.; FRESSOLI, M. En búsqueda de una metodología para investigar Tecnologías Sociales. In: DAGNINO, R. P. (Org.). Tecnologia social: ferramenta para construir outra sociedade. Campinas: IG; Unicamp, 2009.

VIEIRA PINTO, A. Ideologia e desenvolvimento nacional. Rio de Janeiro: Iseb, 1956.

VIEIRA PINTO, A. O conceito de tecnologia. Rio de Janeiro: Contraponto, 2005. V. 1.

VIOTTI, E. B. Brasil: de política de C\&T para política de inovação? Evolução e desafios das políticas brasileiras de ciência, tecnologia e inovação In: Avaliação de políticas de ciência, tecnologia e inovação: diálogo entre experiências internacionais e brasileiras. Brasília: Centro de Gestão e Estudos Estratégicos, 2008.

Recebido em: 27/2/2011

Aceito em: 3/5/2011 